\title{
Nasopharyngeal angiofibroma: Our experience and literature review
}

\author{
Mariane Barreto Brandão Martins', Francis Vinicius Fontes de Lima', Carlos Alberto Mendonça², Eduardo Passos Fiel de Jesus ${ }^{3}$, \\ Arlete Cristina Granizo Santos ${ }^{3}$, Valéria Maria Prado Barreto ${ }^{4}$, Ronaldo Carvalho Santos Júnior 5 .
}

\author{
1) Resident Doctor in the Department of Otolaryngology of the Federal University of Sergipe. \\ 2) Professor in the Department of Head and Neck Surgery. \\ 3) Professor in the Department of Otolaryngology. \\ 4) Masters in Health Sciences, Universidade Fedreral de Sergipe. Professor in the Department of Otolaryngology \\ 5) Doctor of Medicine by USP. Service chief medical residency in Otorhinolaryngology, Universidade Federal de Sergipe. \\ Institution: Universidade Federal de Sergipe. \\ Aracajú / SE - Brazil \\ Mailing address: Mariane Barreto Brandão Martins - Rua Deputado Antônio Torres, 699 - Cond Vila do Sol - Apt 102 A - Aracajú / SE - Brazil - Zip code: $49052-050$ \\ - Telephone: (+55 79) 9924-4118 ou (+55 79) 3222-8388 - E-mail: mari.ane_martins@yahoo.com.br \\ Article received in August 21, 2012. Article accepted in October 7, 2012.
}

\section{SUMMARY}

Introduction: Juvenile nasopharyngeal angiofibroma is a rare, highly vascular, and histologically benign tumor, generally observed in male adolescents. It shows very aggressive behavior due to local invasiveness and is associated with various symptoms. Juvenile nasopharyngeal angiofibroma originates in the sphenopalatine forame, causing epistaxes and nasal obstruction. Objective: To retrospectively describe our experience in the diagnosis and treatment of patients with juvenile nasopharyngeal angiofibroma.

Scientific drawing: Retrospective, descriptive study conducted after approval from the Ethics Committee of the Federal University of Sergipe (protocol 0114.0.107.000-11).

Methods: We analyzed findings in 20 patients who underwent surgery between 2004 and 2011. Factors analyzed include patient age and gender, symptoms, stages, treatment, length of surgery, intraoperatory bleeding, postoperative need for nasal tampons, hospitalization time, complications, and tumor recurrence.

Results: Patients were aged 10-29 years. All patients were treated surgically, including 17 who underwent endoscopic surgery. The mean operation time was $120 \mathrm{~min}$, and the mean bleeding volume was $300 \mathrm{~mL}$. Seventeen patients required clamping of the external carotids and tumor embolization.

Conclusion: Endoscopic surgery alone or with other conventional techniques was safe for the treatment of angiofibromas of different stages.

Keywords: angiofibroma, embolization, therapeutic, epistaxis.

\section{INTRODUCTION}

Nasopharyngeal angiofibroma is a histologically and biologically benign tumor with aggressive behavior due to its location and associated symptoms including significant epistaxis and nasal obstruction (1-5). These tumors occur almost exclusively in male adolescents and account for $0.05 \%-0.5 \%$ of all head and neck tumors $(1,5,6,7)$. The tumors are frequently located in the posterolateral wall of the nasal cavity, where the sphenoid process of the palatine bone articulates with the base of the pterygoid process, forming the sphenopalatine foramen. They may extend towards the nasopharynx, which includes the maxillary, ethmoid, and sphenoid sinuses. Laterally, these tumors may extend to and fill the pterygomaxillary fossa, causing the posterior wall of the maxillary sinus to bulge and eroding the pterygoid plate. Tumors that further extend into the infratemporal fossa may progress into the orbit, through the inferior orbital fissure and to the base of the skull through the base of the pterygoid process. From a triangular region formed by the foramen ovale, a round and lacerated tumor may reach the middle fossa, migrating to the parasellar region and remaining generally extradual and lateral to the cavernous sinus. Rarely, the tumor may destroy the posterior sphenoid sinus and invade the cavernous sinus, pituitary, and/or optic chiasm. Tumors may invade the anterior fossa through the ethmoid and sphenoid sinuses, being more frequent in the middle fossa and remaining extradural $(8,9,10)$. The classic triad of epistaxis, unilateral nasal obstruction, and a mass in the nasopharynx suggests a diagnosis of nasopharyngeal angiofibroma and is supplemented by imaging $(11,12,13,14,15)$. A biopsy is recommended only in cases of diagnostic uncertainty 4 . Examinations such as computed tomography, nuclear magnetic resonance and even nasal endoscopy can clearly establish the extent of the tumor, its pattern of spread, and consequently, surgical planning $(10,11,12,16,17,18,19)$.

These tests have led to the formulations of multiple classification methods, including the Fisch (1983), RADKOWSKI 
(1996), Andrews (1989), Bremer (1986), and Antonelli (1987) methods $(1,4,5,7,8)$. These classifications are very important in helping surgeons decide the appropriate surgical approach.

\section{Classification of Fisch}

Type I: The tumor is limited to the sphenopalatine foramen, nasopharynx, and nasal cavity without bone destruction.

Type II: The tumor invades the nasal sinuses or the pterygomaxillary fossa with bone destruction.

Type IIIa: The tumor invades the infratemporal fossa or orbit without intracranial involvement.

Type IIIb: The tumor invades the infratemporal fossa or orbit with intracranial extradural commitment.

Type IVa: The tumor shows intracranial extradural and/or intradural invasion, without invasion of the optic nerve, sella, or cavernous sinus.

Type IVb: The tumor shows intracranial extradural and intradural invasion, with invasion of the optic nerve, sella, and/or cavernous sinus.

Non-surgical treatments are available, including the use of hormones (estrogen, testosterone), radiation therapy, chemotherapy, and recently, embolization; however, surgery is considered the treatment of choice, with the route depending on the stage of the tumor and the overall condition of the patient $(11,12,14)$.

Vascularization arises most frequently from the maxillary artery (i.e., external carotid system), with background vascularization arising from blood vessels originating in the ascending pharyngeal artery or internal carotid artery (mandibularbranch or inferolateral trunk) (9).

Surgical approaches for conventional techniques include transpalatal, transmaxillary, lateral rhinotomy, midfacial degloving, extended sublabial Denker, and Le Fort type I osteotomy $(11,13,20,21)$. The development of minimally invasive techniques has led to the increased use of endoscopic surgery for the treatment of nasopharyngeal angiofibroma (21), making it ideal for tumors confined to the nasopharynx, nasal cavity, and sphenoid sinus with minimal extension into the pterygopalatine fossa $(10,12,13,15,18,22)$. The first description of an endoscopic resection was published in 1996 (10). Since then, several cases have been reported, all showing that endoscopic resection resulted in lower morbidity during the early stages of disease (10).

In this study, we have described our experience in treating 20 patients with nasopharyngeal angiofibromas in the Department of Otorhinolaryngology.

\section{Methods}

We analyzed 20 patients with nasopharyngeal angiofibroma whounderwent surgery in the otolaryngology service between 2004 and 2011. Variables analyzed included patient age, sex, symptoms, tumor stage, treatment, duration of surgery, volume of intraoperative bleeding, need for nasal packing after surgery, length of hospitalization, immediate and late complications, recurrence, and preoperative embolization and clamping of the external carotid during surgery. All patients were classified radiologically and surgically according to the Fisch system.

\section{RESULTS}

The mean patient age was 16 years, with patients ranging in age from 10 years (Fisch class IIIA) to 29 years (Fisch class II). All patients were male, and all had symptoms of progressive nasal obstruction and recurrent epistaxis. Five patients (25\%) were classified as Fisch I, 12 (60\%) as Fisch II, 2 (10\%) as Fisch IIIA, and 1 (5\%) as Fisch IV (Figure 1).

Surgical methods in all patients were based on Fisch classifications. Of the 20 patients, 3 had surgery by combined approaches (conventional and endoscopic), including 1 patient with a Fisch IIIA tumor who was treated by the Caldwell-Luc expanded technique and endoscopic surgery, 1 patient with a Fisch IIIA tumor who was treated by the degloving mid-facial technique and endoscopic surgery, and 1 with a Fisch IV tumor who was treated by the degloving mid-facial technique associated with craniotomy and endoscopic surgery. The other 17 patients underwent endoscopic surgery alone.

In the 17 patients who underwent endoscopic approach alone, the mean operation time was $120 \mathrm{~min}$ and the mean blood loss was $300 \mathrm{~mL}$; none required replacement of blood products. None of these patients required

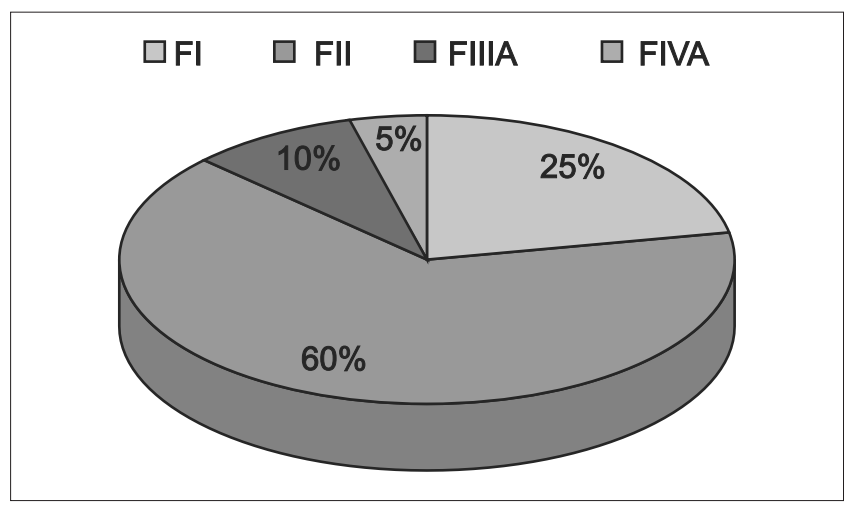

Figure 1. Fisch ratings (F) of angiofibromas. 

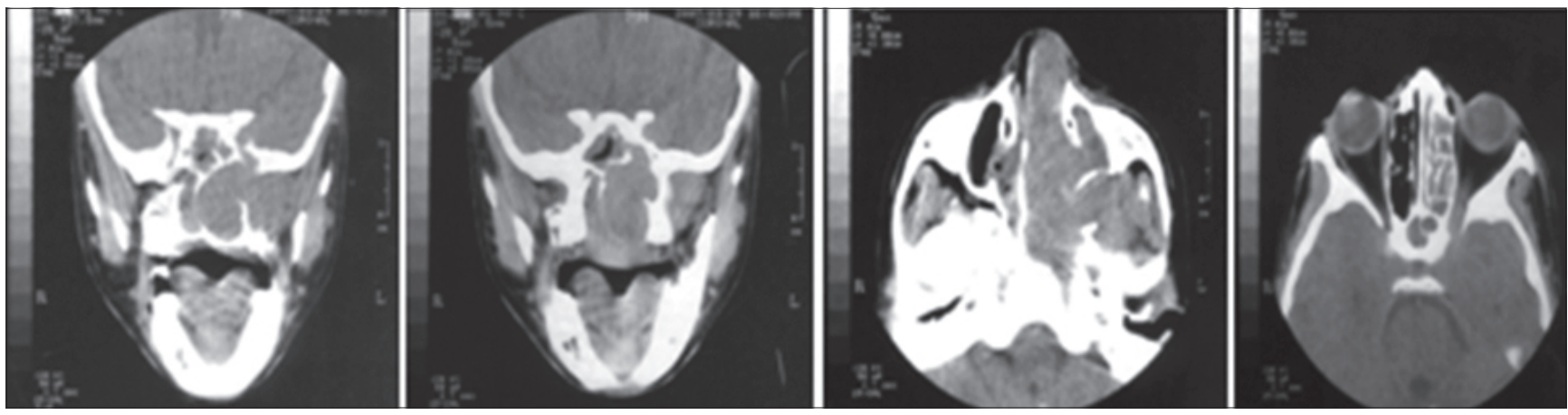

Figure 2. Computed tomography of a 10-year-old patient with a Fisch class IIIa juvenile nasopharyngeal angiofibroma.

postoperative nasal packing, and all were discharged the day after surgery. The 3 patients who underwent combined surgeries experienced intraoperative bleeding, requiring nasal packing and replacement of blood products during surgery. All 20 patients were available for follow-up (maximum, 7 years), with none showing evidence of tumor recurrence.

The first patient who underwent surgery in our department had a Fisch I tumor, but did not undergo embolization or clamping of the external carotid arteries. The second patient, also with a Fisch I tumor, underwent clamping of the external carotid arteries without embolization. The third patient with a Fisch I tumor underwent surgery with embolization, but without clamping of the external carotid arteries. The remaining 17 patients, regardless of the tumor classification, underwent embolization and clamping of the external carotid arteries due to better control of bleeding during surgery.

\section{DISCUSSION}

Juvenile nasopharyngeal angiofibromas present almost exclusively in men aged 14-25 years (23-28). Similarly, our patients ranged in age from 10 to 29 years, with a mean age of 16 years, and all were male.

Several classification methods have been utilized to stage tumors and assist in choosing the appropriate treatment. These classification systems are based on examination methods, including CT, MRI, and endoscopy, and have been utilized to establish the extent of the tumor, its pattern of spread, and consequently, surgical planning $(10,11,12,16,17,18,19)$. Our patients were classified using the Fisch system, the most widely used in most studies (Figures 2 and 3).

Several surgical approaches have been utilized for the removal of nasopharyngeal angiofibromas, including transnasal, transpalatal, transzygomatic, and transcervical
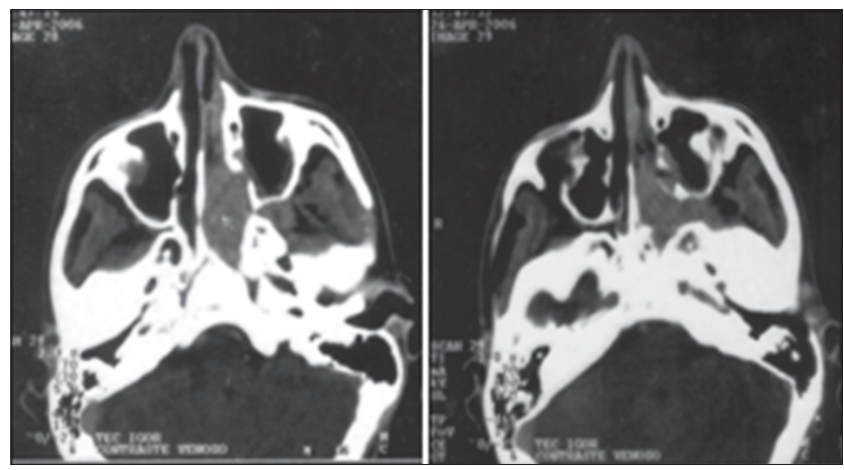

Figure 3. CT of a 14-year-old patient with a Fisch class II juvenile nasopharyngeal angiofibroma.

accesses, in addition to lateral rhinotomy and mid-facial degloving, with or without extension to the upper lip or concomitant craniotomy (9). The combination of different accesses to the tumor can be required (9). Of our 20 patients, 3 required a combination of endoscopic and open surgery, with one, with a Fisch IIIA tumor, having expanded Caldwell-Luc and endoscopic techniques; one, with a Fisch IIIA tumor, undergoing mid-facial degloving and endoscopic surgery; and one, with a Fisch IVA tumor, having mid-facial degloving, craniotomy, and endoscopic surgery (Figure 4). The other 17 patients required only endoscopic surgery.

Longer duration of surgery is associated with greater changes in body homeostasis due to surgical trauma. Improvements in surgical techniques are designed to shorten surgical time and thereby reduce patient morbidity. Endoscopic surgery is less invasive than open surgery, causing less damage to the patient. Consistent with previous results, we found that the mean operation time in the 17 patients who underwent endoscopic surgery alone was $120 \mathrm{~min}$ (14). Moreover, the mean blood loss in these patients was $300 \mathrm{~mL}$. This relatively low blood loss may be due to the use of surgical endoscopy, providing better control of bleeding than open surgery, with or without endoscopy. 

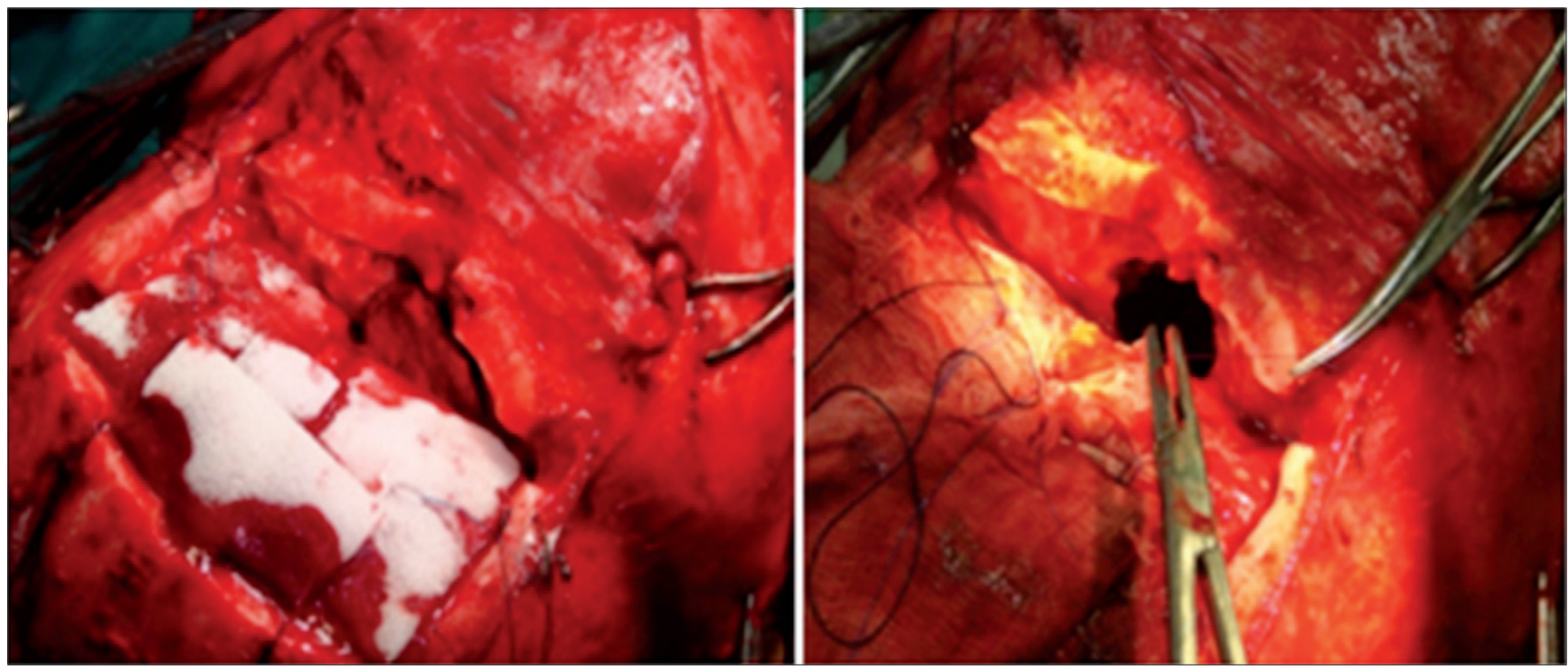

Figure 4. Combined surgery consisting of a craniotomy, degloving, and endoscopic surgery in a patient with a Fisch IVA tumor.

Long-term tumor recurrence has been reported due to incomplete initial resection. For example, a retrospective study of 15 patients found tumor recurrence in 1 patient (6.6\%) (23), and another series of 15 patients showed that 1 patient had a residual lesion on follow-up 24 months later (16). The recurrence rate of endoscopically resected tumors has been shown to be low, and we found that none of our 20 patients experienced tumor recurrence. This may have been due to their relatively early diagnosis, when tumors are found smaller and easier to remove completely, as well as due to the use of endoscopic surgery, which assists in controlling tumor removal, including more accurate examinations of the spaces previously occupied by the tumor.

Many studies highlight the benefit of preoperative arterial embolization to control bleeding intraoperative $(16,29,30)$. Studies comparing surgical treatment with or without embolization have shown that preoperative embolization reduced intraoperative blood loss and the need for replacement of blood products $(31,32)$. Blood loss, which was 836-1200 $\mathrm{mL}$ in a non-embolized patient, was reduced to $400-600 \mathrm{~mL}$ in embolized patients (3133). Ideally, the time between the completion of embolization and the endoscopic procedure should be as small as possible, approximately $24-72 \mathrm{~h}$ (16). Of our 20 patients, only 2 underwent surgery without embolization, with these 2 showing significantly greater intraoperative bleeding than the 18 patients who underwent embolization. Tumor size was not associated with bleeding. The 18 patients who underwent embolization did so $48-72 \mathrm{~h}$ prior to surgery (Figure 5).

Some surgeons, however, do not routinely perform embolization preoperatively, finding that embolization is

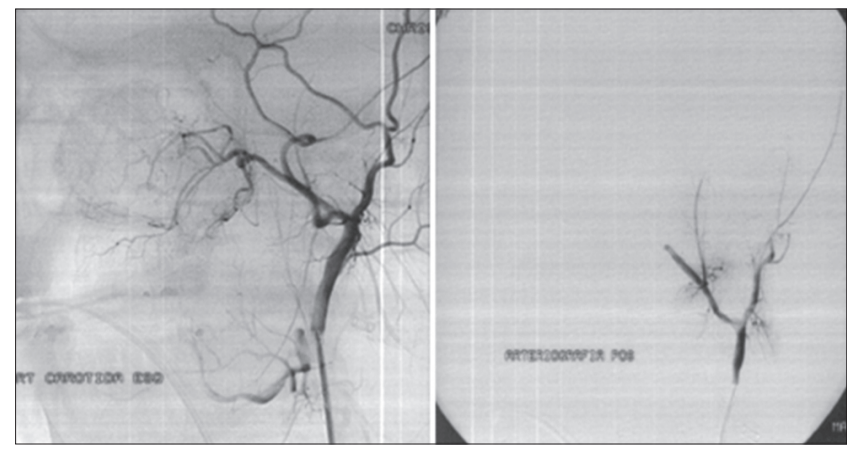

Figure 5. Embolization of a 16-year-old patient with a Fisch IIIa juvenile nasopharyngeal angiofibroma.

justified only in larger tumors (32). The volume of intraoperative bleeding has been shown to be similar in patients with and without embolization (34), whereas tendency to relapse was greater in patients undergoing embolization. In addition, preoperative embolization may complicate the identification of the full extent of surgical margins by reducing the tumor size and increasing the risk of relapse (35).

None of our patients experienced complications due to embolization. However, as in any invasive procedure, embolization presents risks that should be fully explained to the patients (36). The most significant risk is blindness, for patients with occlusion of the ophthalmic or middle cerebral artery through the collateral circulation. To minimize complications, surgery should be performed at centers with extensive experience.

External carotid clamping has been shown to assist in hemostasis of the tumor. Intraoperative control of 
bleeding during the resection of nasopharyngeal angiofibromas can be achieved successfully by temporary clamping of the external carotid arteries in the neck (37). Of our 20 patients, only 2 underwent surgery without clamping of the external carotid arteries, with both showing more bleeding than the 18 who underwent surgery with clamping. Tumor volume was not associated with bleeding in patients with and without clamping. We also found that patients who underwent clamping of the external carotid artery and embolization showed less intraoperative bleeding than patients who underwent embolization alone. Patients undergoing embolization require external carotid clamping due to collateral circulation, which can increase bleeding.

\section{CONCLUSION}

Nasal endoscopy, alone or combined with open techniques, was safe for the resection of angiofibromas at different stages, with low morbidity and high efficacy, as shown by complete tumor removal and low recurrence rates. Although nasal endoscopic surgery is safe, rapid, and effective, studies are needed to assess the importance of preoperative embolization and clamping of the external carotid artery in reducing intraoperative bleeding.

\section{REFERENCES}

1. Mena CC, Bogado GR, Klassen CZ. Nuestra experiência em los últimos 10 anos y revisión de La literatura. An ORL Méx. 2009;69:243-8.

2. Gaeta MM. Nasoangiofibroma juvenil frecuencia. Incidencia de acuerdo a grupo sanguíneo. An ORL Méx. 2005;50:17-21.

3. Wylie JP, Slevin NJ, Johnson RJ. Intracranial juvenile nasopharyngeal angiofibroma. Clin Oncol. 1998;10:330-3.

4. Sanchez de Guzman G. Experiencia en el manejo de nasoangiofibroma juvenil en el Instituto Nacional de Cancerología. Arch Otolaryngol Head Neck Surg. 1999;27(3):653-6.

5. Sociedade Brasileira de Otorrinolaringologia. Tratado de otorrinolaringologia. 2 Ed. São Paulo:Roca Biomedicina; 2003.p.701.

6. Dillard DG, Cohen C, Muller S, Del Gaudio J, Reichman $\mathrm{O}$, Parrish $\mathrm{B}$ et al. Immunolocalization of Activated Transforming Growth Factor 1 in Juvenile Nasopharyngeal Angiofibrom. Arch Otolaryngol Head Neck Surg. 2000;126:723-5.
7. Mcafee WJ, Morris CG, Andur RJ, Werning JW, Mendenhall WM. Definitive Radiotherapy for Juvenile Nasopharyngeal Angiofibroma. Am J Clin Oncol. 2006;29:168-70.

8. Pryor SG, Moore EJ, Kasperbauer JL. Endoscopic versus Traditional Approaches for Excision of Juvenile Nasopharyngeal Angiofibroma. Laryngoscope. 2005;115:1201-7.

9. Carvalho Júnior RS, Mendonça CA, D'Ávila JS, Santos ACG, Jesus EPF, Sobral PM. Abordagem endoscópica no tratamento do nasoangiofibroma: relatode caso. BrazJOtorhinolaryngol. 2005;71(3):4-19.

10. Bernal-Sprekelsen M, Alobid I, Guilemany JM. Angiofibroma Juvenil. Acta Otorrinolaryngol. 2007;58(1):84-95.

11. Hervé S, Portier F, Chapot R. Fibroma Nasofaríngeo. Encyclopedie Medico-Chirurgicale-Otorrinolaringologia. 2001- E-20-585-A-10.

12. Luiz ACR, Romualdo SLT, Fava AS. Angiofibroma nasofaríngeo: revisão de literatura. BrazJ Otorhinolaryngol. 2003;69(3):394-03.

13. Alves FRA, Granato L, Maia MS. Acessos Cirúrgicos no Angiofibroma Nasofaríngeo Juvenil- Relato de caso e revisão de literatura. Arch Otolaryngol Head Neck Surg. 2006;10(2):162-6.

14. Enepekides DJ. Recent advances in the treatment of juvenile angiofibroma. Arch Otolaryngol Head Neck Surg. 2004;12:495-9.

15. Ferreira LMBM, Gomes EF, Azevedo JF. Ressecção Endoscópica de Nasoangiofibroma. BrazJ Otorhinolaryngol. 2006;72(4):475-80.

16. Nicolai P, Berlucchi M, Tomenzoli D. Endoscopic Surgery for Juvenile Angiofibroma: When and How. Laryngoscope. 2003;113:775-82.

17. Maurice M, Milad M. Pathogenisis of Juvenile Nasopharyngeal Fibroma (A new concept). Braz J Otorhinolaryngol. 1981;95:1121-26.

18. Andrade NA, Pinto JA, Nóbrega MO. Exclusively Endoscopic Surgery for Juvenile Nasopharyngeal Angiofibroma. Arch Otolaryngol Head Neck Surg. 2007;137:492-6.

19. Gusso JL, Souza RP, Rapoport A. Nasoangiofibroma Juvenil: concordância interobservadores no estadiamento por tomografia computadorizada. Radiol Bras. 2001;34(4):207-11 
20. Alborno T, Hofmann Th, Stammberger H. Endoscopic Ressection of Juvenile Angiofibroma: Long term results. Rev JRMS. 2005;12(2):18-24.

21. Mair EA, Battiata A, Casler JD. Endoscopic Laser-assisted excision of juvenile nasopharyngeal angiofibromas. Arch Otolaryngol Head Neck Surg. 2003;129:454-9.

22. Yotakis I, Eleftheriadou A, Davilis D. Juvenile Nasopharyngeal Angiofibroma stages I and II: A comparative study of surgical approches. Int J Pediatr Otorhinolaryngol. 2008;72:793-800.

23. Mann WJ, JeckerP, Amedee RG. Juvenile Angiofibromas: changing surgical concept over the last 20 years. Laryngoscope. 2004;114:291-3.

24. Neel HB, Whicker JH, Devine KD. Angiofibroma rewiew of 120 cases. Am J Surg. 1973;126:547-56.

25. Brenner JW, Neel HB, De Santo LW, Jones GC. Angiofibroma: Treatment trends in 150 patients during 40 years. Laryngoscope. 1986;96:1321-9.

26. Tran BHP, Borsik M, Hermam P, Wasser M, Casasco A. Direct intratumoral embolization of juvenile angiofibroma. Am J Otolaryngol. 1994;15:429-35.

27. Sekhar LN, Janecka IP. Surgery of cranial base tumors. New York: Raven Press; 1993.p. 485.

28. Ferreira LHBM, Gomes EF, AzevedoJF, Souza JRF, Araujo RP, Rios ASN. Ressecção endoscópica de nasoangiofibroma. Braz J Otorhinolaryngol. 2006; 72:475-80.

29. Katsiotis P, Tzortzis G, Karaminis C. Transcatheter arterial embolization in nasopharyngeal angiofibroma. Acta Radiol Diagn. 1979;20(3):433-8.
30. Roger G, Tran Ba Huy P, Froehlich P, Van Den Abbeele T, Klossek JM, Serrano E et al. Exclusively endoscopic removal of juvenile nasopharyngeal angiofibroma: trends and limits. Arch Otolaryngol Head Neck Surg. 2002;128(8):928-35.

31. Li JR, Qian J, Shah XZ. Evaluation of the effectiveness of preoperative embolization in surgery for nasopharyngeal angiofibroma. Arch Otolaryngol Head Neck Surg. 1998;255:430-2.

32. Moulin G, Chagnaud C, Gras R, Gueguen E, Dessi P, Gaubert JY et al. Juvenile nasopharyngeal angiofibroma: comparison of blood loss during removal in embolized group versus nonembolized group. Cardiovasc Intervent Radiol. 1995;18(3):158-61.

33. Christensen NP, Smith DS, Barnwell SL, Wax MK. Arterial embolization in the management of posterior epistaxis. Arch Otolaryngol Head Neck Surg. 2005;133(5):748-53.

34. Petruson K, Rodriguez CM, Petrusin B, Finizia C. Juvenile nasopharyngeal angiofibroma: long-term results in preoperative embolized and nonembolized patients. Acta Otolaryngol. 2002;122(1):96-100.

35. McCombe A, Lund VJ, Howard DJ. Recurrence in juvenile angiofibroma. Rhinology. Acta Otolaryngol. 1990;28:97-102.

36. Gay I, Elidan J, Gordon R. Oronasal fistula a possible complication of preoperative embolization in the management of juvenile nasopharyngeal angiofibroma.J Laryngol Otol. 1983;97(7):651-6.

37. Gomes LF, Morelo MZ, Oliveira CA. Angiofibroma de nasofaringe:Controle do sangramento intraoperatótio por oclusão parcial das carótidas externas. Braz J Otorhinolaryngol. 1984;11(6):167-9. 